Western University Scholarship@Western

Electrical and Computer Engineering Publications Electrical and Computer Engineering Department

4-2006

\title{
A Multicultural Comparison of Engineering Students
}

\author{
Zaki Shakir Seddigi \\ zseddigi@gmail.com \\ Luiz Fernando Capretz \\ University of Western Ontario, lcapretz@uwo.ca
}

Follow this and additional works at: https://ir.lib.uwo.ca/electricalpub

Part of the Bilingual, Multilingual, and Multicultural Education Commons, Engineering Education Commons, and the Other Engineering Commons

\section{Citation of this paper:}

Seddigi, Zaki Shakir and Capretz, Luiz Fernando, "A Multicultural Comparison of Engineering Students" (2006). Electrical and Computer Engineering Publications. 77.

https://ir.lib.uwo.ca/electricalpub/77 


\section{A Multicultural Comparison of Engineering Students}

\author{
Zaki S. Seddigi \\ King Fahd University of Petroleum and Minerals \\ Chemistry Department \\ Dhahran, Zip Code 31261, Saudi Arabia \\ zseddigi@kfupm.edu.sa
}

\author{
Luiz Fernando Capretz \\ University of Western Ontario \\ Dept. of Electrical \& Computer Engineering \\ London, Ontario, Canada N5A 5B9 \\ lcapretz@eng.uwo.ca
}

\begin{abstract}
A multicultural personality profile of engineering students is presented in this work. The Myers-Briggs Type Indicator (MBTI) was used as an instrument to sort personality types of engineering students at both King Fahd University of Petroleum and Minerals in Saudi Arabia and University of Western Ontario in Canada. The paper discusses the differences and similarities in the personality profile of Saudi and Canadian engineering students and its implications for engineering education in the light of the MBTI scales.
\end{abstract}

\section{Introduction}

Many teachers believe that being fair means treating all students equally. If this translates into using the same approach with every student or treating students identically, then problems are likely to arise for many students who may feel left out because of teachers' choice of classroom activities biased by their own teaching style. For example, Zaki and Overton [1] observed student's impressions of a series of open-ended group problem solving exercises; they recommend that instructors should select the group members, not the students, because good students like to work with each other and weak students will end up working together.

Educators have been using the Myers-Briggs Type Indicator (MBTI) [2] to develop teaching methods, and to understand both individual learning styles and differences in motivation. In short, the MBTI sorts four scales of preferences, but one side from each dimension is used to define a type. Of course, people can and do use all eight preferences in each of the four pairs, but we all have one preference that works better for us than its opposite:

a) Extroversion and introversion (E and I): Some people are oriented to a breadth-of-knowledge approach with quick action; others are oriented to a depth-of-knowledge approach reflecting on concepts and ideas. Jung calls these orientations extroversion and introversion.

b) Sensing and Intuition (S and $\mathrm{N}$ ): Some people are attuned to the practical, hands-on, commonsense view of events, while other are more attuned to the complex interactions, theoretical implications, or new possibilities of events.
These two styles of information gathering, or perception, are known as sensing or intuition, respectively.

c) Thinking and feeling ( $\mathrm{T}$ and $\mathrm{F}$ ): Some people typically draw conclusions or make judgments dispassionately and analytically; others weigh the human factors or societal import, and make judgments with personal conviction as to their value. These two styles of decision-making are called thinking or feeling, respectively.

d) Judgment and perception ( $\mathrm{J}$ and $\mathrm{P}$ ): Finally, some people prefer to collect only enough data to make decisions before setting on a direct path to a goal, and typically stay on that path. Others are finely attuned to changing situations, alert to new developments that may require a change of strategy, or even a change of goals. These two styles are called the preferences for judgment or perception, respectively.

Hence, there are 16 possible configurations, as shown in Table 1. If the MBTI results show that a person is ISTP, then the terminology is to suggest that the person prefers ISTP.

Table 1. The 16 MBTI types and their distribution among the U.S. adult population.

\begin{tabular}{|l|l|l|l|}
\hline ISTJ & ISFJ & INFJ & INTJ \\
$11.6 \%$ & $13.8 \%$ & $1.5 \%$ & $2.1 \%$ \\
\hline ISTP & ISFP & INFP & INTP \\
$5.4 \%$ & $8.8 \%$ & $4.4 \%$ & $3.3 \%$ \\
\hline ESTP & ESFP & ENFP & ENTP \\
$4.3 \%$ & $8.5 \%$ & $8.1 \%$ & $3.2 \%$ \\
\hline ESTJ & ESFJ & ENFJ & ENTJ \\
$8.7 \%$ & $12.3 \%$ & $2.5 \%$ & $1.8 \%$ \\
\hline
\end{tabular}

\section{Canadian Engineering Students}

Many people outside the engineering area seem to have ideas and stereotypes about what engineers are like and what attract them to the engineering field. Rosati [3] shows the type distribution of 1,252 Canadian students successful in their first-year in engineering programs at the University of Western Ontario, as summarized in Table 2. The sample distribution is believed to be similar to other samples found in engineering majors at different universities across the United States and Canada.

The results show that ISTJ, ESTJ, INTJ and INTP compose over $50 \%$ of the sample, thus significantly 
over-represented; whereas ESFP, ESFJ and ENFJ are all particularly under-represented in that group. The study found more introverts ( $\mathrm{I}=61 \%)$ than extroverts ( $\mathrm{E}=39 \%)$; slightly more sensing $(\mathrm{S}=55 \%)$ than intuitive $(\mathrm{N}=45 \%)$ types; significantly more thinking $(\mathrm{T}=75 \%)$ than feeling ( $\mathrm{F}=25 \%)$ types; and less perceiving $(\mathrm{P}=43 \%)$ compared to judgment $(\mathrm{J}=57 \%)$ types.

Table 2. Type distribution of Canadian engineering students, $(N=1,252)$.

\begin{tabular}{|l|l|l|l|}
\hline ISTJ & ISFJ & INFJ & INTJ \\
$\mathrm{N}=244$ & $\mathrm{~N}=41$ & $\mathrm{~N}=38$ & $\mathrm{~N}=126$ \\
$19.5 \%$ & $3.3 \%$ & $3.0 \%$ & $10.1 \%$ \\
\hline ISTP & ISFP & INFP & INTP \\
$\mathrm{N}=102$ & $\mathrm{~N}=36$ & $\mathrm{~N}=54$ & $\mathrm{~N}=124$ \\
$8.2 \%$ & $2.9 \%$ & $4.3 \%$ & $9.9 \%$ \\
\hline $\mathrm{ESTP}$ & $\mathrm{ESFP}$ & $\mathrm{ENFP}$ & $\mathrm{ENTP}$ \\
$\mathrm{N}=68$ & $\mathrm{~N}=30$ & $\mathrm{~N}=45$ & $\mathrm{~N}=85$ \\
$5.4 \%$ & $2.4 \%$ & $3.6 \%$ & $6.8 \%$ \\
\hline $\mathrm{ESTJ}$ & $\mathrm{ESFJ}$ & $\mathrm{ENFJ}$ & $\mathrm{ENTJ}$ \\
$\mathrm{N}=136$ & $\mathrm{~N}=31$ & $\mathrm{~N}=29$ & $\mathrm{~N}=63$ \\
$10.9 \%$ & $2.5 \%$ & $2.3 \%$ & $5.0 \%$ \\
\hline
\end{tabular}

\section{Saudi Engineering Students}

Our subjects comprise a group of engineering students attending the King Fahd University of Petroleum and Minerals. Ninety-six engineering students were invited to participate in the study, and were administered the MBTI (Form G) to determine their personality types. The type distribution of these Saudi students is summarized in following Table 3

This study has shown that ESTJ, INTJ and INTP compose almost $40 \%$ of the sample, therefore, overrepresented. On the other hand, ISTP, ESTP, ISFP, and ESFJ are all particularly underrepresented in this Saudi sample. This research also found almost the same proportion of introverts ( $\mathrm{I}=49 \%)$ than extroverts $(\mathrm{E}=51 \%)$ types; fairly less sensing ( $\mathrm{S}=36 \%)$ than intuitive $(\mathrm{N}=64 \%)$; significantly more thinking $(\mathrm{T}=66 \%)$ than feeling $(\mathrm{F}=34 \%)$; and slightly more judging $(\mathrm{J}=60 \%)$ compared to perception $(\mathrm{P}=40 \%)$ type.

Table 3. Type distribution of Saudi engineering students, $(\mathrm{N}=96)$.

\begin{tabular}{|c|c|c|c|}
\hline ISTJ & ISFJ & INFJ & INTJ \\
$\mathrm{N}=7$ & $\mathrm{~N}=3$ & $\mathrm{~N}=7$ & $\mathrm{~N}=15$ \\
$7.3 \%$ & $3.1 \%$ & $7.3 \%$ & $15.6 \%$ \\
\hline $\mathrm{ISTP}$ & ISFP & INFP & INTP \\
$\mathrm{N}=2$ & $\mathrm{~N}=1$ & $\mathrm{~N}=6$ & $\mathrm{~N}=6$ \\
$2.1 \%$ & $1.0 \%$ & $6.3 \%$ & $6.3 \%$ \\
\hline $\mathrm{ESTP}$ & $\mathrm{ESFP}$ & $\mathrm{ENFP}$ & $\mathrm{ENTP}$ \\
$\mathrm{N}=2$ & $\mathrm{~N}=7$ & $\mathrm{~N}=3$ & $\mathrm{~N}=11$ \\
$2.1 \%$ & $7.3 \%$ & $3.1 \%$ & $11.5 \%$ \\
\hline $\mathrm{ESTJ}$ & $\mathrm{ESFJ}$ & $\mathrm{ENFJ}$ & $\mathrm{ENTJ}$ \\
$\mathrm{N}=11$ & $\mathrm{~N}=2$ & $\mathrm{~N}=4$ & $\mathrm{~N}=9$ \\
$11.5 \%$ & $2.1 \%$ & $4.2 \%$ & $9.4 \%$ \\
\hline
\end{tabular}

\section{Discussion}

Although there are many similarities in the type distribution of Canadian and Saudi students, it is worth noticing that there are more ISTJ (19.5\%) in the Canadian sample, and INTJ (15.6\%) in the Saudi sample, than any other type respectively. The biggest discrepancies occur in the ISTP and ESFP cells, $8.2 \%$ as opposed to $2.1 \%$, and $2.4 \%$ against $7.3 \%$, respectively; the other remaining numbers for the other cells are more in accordance. It came as a surprise to find almost the same percentage of STs (23\%) and NFs (21\%) in the Saudi subjects, which is unusual in engineering schools in North America.

It can also be noted that STs comprise almost $44 \%$ of the Canadian, against $23 \%$ in the Saudi sample. SFs appear 11\% among Canadian engineering students and $13 \%$ among Saudis. NFs are only $13 \%$ in the Canadian side, but $21 \%$ in the Saudi side. Finally, 32\% are NT in Canada, whereas $43 \%$ in Saudi Arabia. But most importantly, it can be clearly seen that both samples contain significantly more NTs and much less SFs than estimated to be in the general population. It is relevant to point out that NTs (43\%) are more common among Saudi engineering students than among the Canadian engineering students (32\%). On the other hand, STs (44\%) can be encountered among Canadian engineering, as opposed to only $23 \%$ among Saudi engineering students.

\section{Final Remarks}

The MBTI theory confirms that the preference that has most conspicuous consequences in education is the choice between the two kinds of perception: sensing and intuition. Sensing focuses interest and attention upon the concrete reality that is apparent to the five senses. Sensing students are most interested in doing something, almost anything, with almost any tangible object, than in listening to what anyone is saying, unless it has to do with action or adds something definite to their picture of the physical world.

In contrast, intuition focuses interest and attention upon the end results of one's own unconscious processes, which include the translation of symbols, that is, words into meaning and vice-versa. Intuitive students thus tend to take a positive interest in languages, spoken and written, and acquire a facility that is convenient in class and in verbal ability tests and also enables them to state clearly usefully to themselves the relationships and possibilities suggested by their intuition.

Kalsbeek [4] stated that "learning can be understood as a person's preferred approach to information processing, idea formation, and decision making; the attitude and interests that influence what is intended to in a learning situation; and a disposition to seek learning environments compatible with these personal profiles”. Thus adjusting instruction to accommodate the learning 
styles of different types of students can increase both achievement and the enjoyment of learning.

We can infer that college students can improve their study habits by knowing their MBTI type and show different learning styles are associated with each preference; advice should also be provided for the student whose learning style conflicts with the instructor's teaching style. Similar accounts of the relation between MBTI type and learning propensities in a software engineering course is described in Capretz [5].

Lawrence [6] also reported that most college students are sensing types. Ambiguity tends to make them feel uncomfortable; they seek certainty, clarity, and explanations concerning the reasons for tasks and assignments; they prefer highly structured, concrete, linear experiences. However, most faculty members tend to prefer intuitive modes of teaching characterized by reflective, abstract ways of looking at the world; teaching in an intuitive mode favours that smaller group of students who learn in this way. The ideal teacher is one who can diagnose learning styles and select, from an armory of skill and techniques, the appropriate strategy for enhancing learning.

According to Williams [7], “today's working environment forces the engineers to collaborate with political scientists, economists, lawyers and managers in all areas. The good news is that engineering education is becoming more and more socialized, consequently demanding engineers with different personality trend. The bad news is that this is happening almost entirely under the aegis of business. Whatever the official curricular requirements, many engineering students regard economics or management (as opposed to science) as a de facto requirement. They are increasingly aware they need to know how society works, which is not necessarily the same thing as an education that highlights social responsibilities. As a result engineering education is currently a contested terrain, a site where different strategic goals collide.”

Additionally, there is a growing need for professionals with diverse expertise to meet the challenges of today's global marketplace, therefore a multidisciplinary approach to engineering education is very much in demand, as indicated by McKee and Berruti [8]. These trends reflect in the myriad of personality types that choose a career in engineering.

Therefore, engineering faculty should recognize that their classes contain all types of learners. Hence, effective instruction should try to make some appeal to each learning style for some of the time in a balanced fashion. That means incorporating activities that require reflection and occasional discussion. Challenge them with problem solving exercises involving abstraction and practice; encourage them to see the tree as well as the forest; give them the opportunity to develop a personal (feeling) touch and whenever possible, tolerate deadline flexibility to cater for the needs of the perceiving types.

In closing, we remind engineering teachers that all types choose engineering. Some types are more likely to stay within the field while others leave. Even so, engineering is losing some atypical students who tried our wares and then sought more fitting studies; it means that we are losing some students of the types which can be important in transforming engineering into a more user-oriented field and in finding new directions for engineering programs in the future. If we can find ways to value the diversity among students, help them to go through the barrier of type and reach niches in the engineering field where they will fit and feel valued, we should thrive to provide alternatives to retain them and enrich the engineering profession.

\section{References}

[1] Seddigi, Z. S. and Overton, T. L., "How Students Perceive Group Problem Solving: The Case of a NonSpecialist Chemistry Class", Journal of Chemistry Educatio: Research \& Practice, Vol. 4, No. 3, pp. 387395, 2003.

[2] Myers, I. B., Introduction to Type, Consulting Psychologists Press, 1998.

[3] Rosati, P. Psychological Types of Canadian Engineering Students, Journal of Psychological Type, Vol. 41, pp. 3337, 1997.

[4] Kalsbeek, D. H., "Linking Learning Style Theory with Retention Research: The TRAILS Project", Association for Institutional Research, Vol. 32, pp. 1-7, 1989.

[5] Capretz, L. F. The Implications of MBTI in Software Engineering Education, ACM SIGCSE Bulletim - Inroads, Vol. 34, No. 4, pp. 134-137, ACM Press, 2002.

[6] Lawrence, G. A., "Synthesis of Learning Style Research Involving the Myers-Briggs Type Indicator", Journal of Psychological Type, Vol. 8, pp. 2-15, 1984.

[7] Williams, R. Retooling: A Historian Confronts Technological Change, MIT Press, 2002.

[8] McKee, J. S. and Berruti, F. Engineering the Future, Engineering Dimensions, pp. 41-42, Professional Engineers of Ontario, July/August 2003. 